\title{
APONTAMENTOS SOBRE EDUCAÇÃO E TRABALHO NO BRASIL CONTEMPORÂNEO: ASPECTOS DA CONTRARREFORMA EDUCACIONAL
}

\author{
Fabiana de Cássia Rodrigues ${ }^{1}$ \\ Luciana Cristina Salvatti Coutinho ${ }^{2}$
}

\begin{abstract}
Resumo
O presente artigo articula a temática da educação e trabalho com os desafios brasileiros em sua inserção na divisão internacional do trabalho, segundo as especificidades de sua formação social, marcada pelo capitalismo dependente e subdesenvolvido. Partimos da formulação das seguintes questões: De que educação necessitam os trabalhadores na realidade brasileira atual, segundo a ótica do capital? O esvaziamento de conteúdos e sentidos da educação estaria em consonância com as mudanças na estrutura ocupacional brasileira? A simplificação dos conteúdos trabalhados na escola traz quais exigências à formação docente? A fim de discuti-las a redação foi dividida em duas partes. Na primeira parte do texto, partiremos dos retrocessos atuais na estrutura produtiva, procurando evidenciar as suas determinações históricas. Coloca-se também em destaque as diretrizes educacionais formuladas pelos organismos multilaterais em consonância com as mudanças na estrutura ocupacional brasileira que contribuem para explicar as políticas que esvaziam a formação das trabalhadoras e trabalhadores. Na segunda parte, trataremos de aspectos da política educacional brasileira que materializam as perspectivas dos organismos multilaterais para a educação no contexto social brasileiro. Foram abordados três aspectos: 1) A elaboração da Base Nacional Comum Curricular; 2) As novas diretivas para formação de professores; 3) O Projeto Escola Sem Partido como mecanismo de pressão para minimizar o caráter formativo da escola. Percebemos que os três aspectos em questão articulados promovem um esvaziamento da escola e da formação de professores de conhecimentos científicos e político-culturais, contrários às reivindicações educacionais na luta pela redemocratização nos anos de 1980, conformando, desse modo, um movimento de contrarreforma.
\end{abstract}

Palavras-chave: Contrarreforma educacional. Base Nacional Comum Curricular. Formação de professores. Escola Sem Partido.

\section{NOTES ABOUT THE EDUCATION AND LABOUR IN CONTEMPORARY BRAZIL: ASPECTS OF THE EDUCATIONAL COUNTER REFORM}

\begin{abstract}
The present work articulates the thematic of education and work with the Brazilian challenges in its insertion in the international division of labor, according to the specificities of its social formation, pronounced by the dependent and underdeveloped Capitalism. We
\end{abstract}


started from the formulation of the following questions: According to the perspective of the bank stock, what sort of education do workers need in the current Brazilian reality? Would the emptying of both contents and significations of the education be in consonance with the changes in the Brazilian occupational structure? Which demands do the simplification of the approached contents bring to the teacher training? In order to debate them, the writing was divided in two parts. In the first part of the text we will start from the current regress in the productive structure, trying to evidence its historical determinations. The educational guidelines formed by the multilateral organizations in consonance with the changes in the Brazilian occupational structure that contribute to explain the policies that empty the education of both male and female workers are also in evidence. In the second part, aspects of the Brazilian educational policy that materialize the perspectives of the multilateral organizations for the education in the Brazilian social context will be approached. Three aspects were considered: 1) The elaboration of the Commom Curricular National Base; 2) The new directives for teachers training; 3 ) The School with no party Project as a mechanism of pressure to minimize the school formative character. We have realized that the three aspects that were articulated promote the emptying of both school and teachers training in scientific and political and cultural knowledge, which are against the educational claims towards the fight for redemocratization in the eighties, conforming, in this way, a counter reform movement.

Keywords: Educational counter reform. Common Curricular National Base. Teachers training. School with no party.

\section{INTRODUÇÃO}

O presente artigo articula a temática da educação e trabalho com os desafios brasileiros em sua inserção na divisão internacional do trabalho. A partir da relação profunda existente entre educação e trabalho, formulam-se alguns questionamentos: De que educação necessitam os trabalhadores na realidade brasileira atual, segundo a ótica do capital? O esvaziamento de conteúdos e sentidos da educação estaria em consonância com as mudanças na estrutura ocupacional brasileira? A simplificação dos conteúdos trabalhados na escola traz quais exigências à formação docente?

Pretendemos discutir neste texto aspectos da realidade concreta brasileira que nos auxiliem a refletir sobre estas questões. Assim, na primeira parte do texto, partiremos de problemas da conjuntura atual procurando evidenciar as determinações da formação histórica brasileira como fundamentais para a compreensão dos retrocessos porque passa o sistema produtivo no Brasil, segundo sua inserção na divisão internacional do trabalho. Colocamos em destaque as diretrizes educacionais formuladas pelos organismos multilaterais juntamente com as mudanças na estrutura ocupacional brasileira que confluem para a formulação de políticas de simplificação da formação das trabalhadoras e trabalhadores.

Bem como trataremos, na segunda parte, das mudanças em curso na política educacional que se coadunam com a realidade do trabalho na contemporaneidade, a partir 
dos seguintes aspectos: 1) A formulação de uma Base Nacional Comum Curricular; 2) As novas diretivas para formação de professores; 3) O Projeto Escola Sem Partido como mecanismo de pressão para o esvaziamento do caráter formativo da escola.

\section{RETROCESSOS ECONÔMICOS E DESAFIOS EDUCACIONAIS NO BRASIL CONTEMPORÂNEO}

Segundo o historiador Caio Prado Júnior (2000), os traços essenciais que determinam a evolução da formação social, econômica e política do Brasil podem ser sintetizados no que ele denominou de sentido da colonização. Este sentido é compreendido numa análise que privilegia a longa duração e a perspectiva da totalidade:

[...] se vamos à essência da nossa formação veremos que na realidade nos constituímos para fornecer açúcar, tabaco, alguns outros gêneros, mais tarde ouro e diamantes; depois, algodão e em seguida café, para o comércio europeu. Nada mais que isto. E com tal objetivo, objetivo exterior, voltado para fora do país e sem atenção a considerações que não fossem o interesse daquele comércio, que se organizarão a sociedade e a economia brasileiras. Tudo se disporá naquele sentido: a estrutura bem como as atividades do país. [...]. (PRADO JÚNIOR, 2000, p. 20).

Segundo Florestan Fernandes (2006), nossa formação social é marcada pela dupla articulação entre subdesenvolvimento e dependência, ou seja, de um lado, ao longo de nossa história são mantidos e recriados setores arcaicos, atrasados em que são mantidas relações de trabalho baseadas na extrema exploração, por outro lado, a economia brasileira não se constitui autonomamente, se mantém atrelada e submetida a interesses externos, funcionando sempre a reboque dos acontecimentos internacionais.

As obras de Caio Prado Júnior (2000) e de Florestan Fernandes (2006) são essenciais para compreendermos os desafios atuais que se colocam para a sociedade brasileira. Apesar de terem sido escritas em meados do século XX, suas interpretações captaram aspectos essenciais de nossa formação histórica que constituem desafios não superados. Caio Prado Júnior ao falar do sentido da colonização, enfatiza o caráter agrário exportador de nossa economia bem como as relações de trabalho marcadas por nosso passado escravista, configurando um quadro de extrema exploração do trabalho. Já Florestan Fernandes mostra os aspectos-chave de nossa Revolução Burguesa que não realiza as reformas democráticas que compuseram as experiências dos países centrais, como a reforma agrária ou a educacional, destacando que, na particularidade do capitalismo brasileiro, estruturas arcaicas são mantidas como condição desse processo e também configuram as bases da extrema exploração do trabalho no país, especialmente no campo (RODRIGUES, 2013). Florestan Fernandes ressalta que no Brasil, especialmente após 1964, a Revolução Burguesa no Brasil se concretiza como um processo contrarrevolucionário, no que tange às reformas democráticas que fizeram parte das experiências históricas clássicas:

[...] a modernização visada sob o lema de "desenvolvimento com segurança" - na lapidar formulação sintética, descoberta nos Estados Unidos - dissocia-se do modelo de civilização imperante nas nações hegemônicas. Ela negligencia ou põe em segundo plano os requisitos igualitários, democráticos e cívico-humanitários da ordem social competitiva, que operariam, na prática, como obstáculos à transição 


\section{Revista HIIST'TEIDBR On-line}

para o capitalismo monopolista. Na periferia essa transição torna-se muito mais selvagem que nas nações hegemônicas e centrais, impedindo qualquer conciliação concreta, aparentemente a curto e a longo prazo, entre democracia, capitalismo e autodeterminação. (FERNANDES, 2006, p. 298).

Prado Júnior (2000) e Florestan Fernandes (2006) demonstram em suas análises os limites do capitalismo brasileiro no que tange às possibilidades de soberania nacional e de estar assentado em bases mais democráticas. Mesmo a industrialização que se realizou no país, caracterizada pelo processo de substituição de importações se fundou em bases frágeis, conforme escreve Maurício Espósito (2016, p. 157):

[...] a industrialização sob o padrão de substituição de importações apresentou um caráter paradoxal. Por um lado, foi um processo em que se verificou uma considerável diversificação produtiva, com a internalização de segmentos complexos e a consecução de um sistema relativamente integrado cujo eixo dinâmico residia no mercado interno. E, por outro, ao ter sido ancorado na modernização dos padrões de consumo, foi um processo em que se intensificaram as principais mazelas responsáveis pelo subdesenvolvimento: a segregação social e a dependência externa.

E hoje pesquisas indicam que se vivencia um processo de desindustrialização no país configurando uma posição mais subalterna na divisão internacional do trabalho (CARNEIRO, 2008; NASSIF, 2006). Segundo pesquisa do professor Wilson Cano (2012), em 2000, 60\% das nossas exportações eram de bens manufaturados, enquanto os bens básicos (não industrializados) representavam 23,4\% do total exportado, já em 2011, há uma inversão na importância desses bens na pauta exportadora, passando os bens manufaturados a representar $36,7 \%$ do total e os bens básicos $48,8 \%$.

A pesquisa de Maurício Espósito (2016) demonstrou que o processo de desregulamentação e o aprofundamento da liberalização econômica a partir dos anos de 1990 desmantelaram as bases que haviam permitido a industrialização por substituição de importações, acarretando a desarticulação do sistema industrial, com a perda da participação da indústria na dinâmica econômica do país, juntamente com a reprimarização da pauta exportadora e a erosão dos centros internos de decisão, por força da submissão do Estado ao capital rentista.

Segundo Plínio de Arruda Sampaio Júnior (2017), a submissão da economia brasileira aos desígnios das políticas neoliberais que privilegiam largamente os interesses dos rentistas internos e externos, a expõe à "[...] fúria da concorrência em tempos de crise [...]" levando a "[...] uma simplificação ainda maior de seu sistema produtivo", não tendo como concorrer com as economias centrais, o único caminho que lhe resta é: "[...] ser relegado à posição terciária de mero fornecedor de produtos primários e semimanufaturados, de baixo conteúdo tecnológico, alto consumo de energia e elevado impacto negativo sobre o meio ambiente". (SAMPAIO JUNIOR, 2017, p. 133).

Este mesmo processo vincula-se à redefinição dos fundamentos da inserção do proletariado precarizado na estrutura ocupacional brasileira:

Se até meados dos anos de 1990 a dinâmica nacional de criação de empregos se concentrava na faixa de 3 a 5 salários mínimos, com a indústria respondendo por 


\section{Revista HIIST'TEIDBR On-line}

40\% das vagas, entre 1994 e 2008 a dinâmica do emprego deslocou-se para os serviços, com 70\% das novas vagas sendo abertas no setor. (BRAGA, 2017, p. 107).

Apesar do crescimento econômico experimentado nos Governos do Partido dos Trabalhadores nos anos 2000, os dilemas do mercado de trabalho se mantiveram:

Entre 2003 e 2014, assistimos no Brasil a um ciclo de desconcentração da renda entre os que vivem dos rendimentos do trabalho, que, no entanto, apresentou limites muito precisos: o mercado brasileiro tem notórias dificuldades de criar empregos mais qualificados do que aqueles facilmente encontrados, por exemplo, no setor de serviços pessoais ou na construção civil. Ademais, as condições de trabalho deterioram-se ao longo dos anos, com o aumento da terceirização empresarial, da taxa de rotatividade e da flexibilização dos contratos, além da elevação do número de acidentes de trabalho no país. (BRAGA, 2017, p. 115-116).

Estes aspectos expressam-se no fato de que além da maior parte dos empregos serem no setor de serviços, a principal ocupação nacional está no emprego doméstico, contando em 2009 com 7,2 milhões de trabalhadoras, em que apenas 38\% possuía carteira assinada. Acompanhadas pelo trabalho no telemarketing, com cerca de 1,4 milhões, em 2012. (BRAGA, 2017).

Assim, é possível indagar quais consequências adviriam dessas mudanças na estrutura produtiva e também quais suas implicações educacionais, em um contexto de reprimarização da economia brasileira, em que as atividades agrícolas e extrativas ganham força. Neste caso, as questões propostas poderiam ser desenvolvidas da seguinte maneira: Qual educação o trabalhador necessita em um país que reitera sua condição dependente e subdesenvolvida? A regressão na estrutura produtiva seria um dos fundamentos explicativos de uma educação esvaziada de conteúdos e sentidos? De que maneira a formação de professores está imbricada nas determinações recíprocas entre educação e trabalho segundo as atuais configurações da produção material da vida e num momento em que o Brasil se insere de maneira ainda mais subalterna na divisão internacional do trabalho?

Trata-se do crescimento exponencial de atividades que requerem modesta escolarização. Conforme escreve Roberto Leher (2014, p. 75):

Com efeito, a despeito da elevação da escolaridade da População em idade Adulta/PIA (formalmente 7,6 anos, 2013), 90\% dos novos empregos formais da última década são postos de trabalho super explorados cuja remuneração não ultrapassa dois salários mínimos. Justamente por manter um grau brutal de exploração do trabalho e inclementes expropriações (como no campo, processo que levou a reconcentração da propriedade fundiária [...]) o país se sobressaiu como um dos mais notáveis emergentes, cujo produto interno bruto/PIB, impulsionado pelas commodities, chegou a constituir o oitavo PIB mundial. Assim é o capitalismo dependente no qual coexistem o dito moderno com o arcaico, como salientou Florestan Fernandes.

[...] Em virtude do fortalecimento do eixo da economia intensiva em recursos naturais [...], da concentração monopólica em umas poucas corporações localizadas em etapas específicas das fracionadas cadeias produtivas [...], da expansão desenfreada do setor de baixa complexidade (onde se situa a juventude que compõe o precariato), do imenso exército industrial de reserva a ser socializado, os setores dominantes compreendem que as escolas podem ser convertidas em um espaço de educação minimalista. 
Prescinde-se, dessa forma, de uma educação com maior complexidade científica e cultural que pode se vincular a uma formação restrita às competências básicas, tal como já estimulado pelo sistema de avaliação educacional adotado pelo Ministério da Educação. Esse conceito de competências básicas remete à Conferência Mundial de Educação para Todos realizada em 1990 em Jomtien (Tailândia) patrocinada, segundo Shiroma, Moraes e Evangelista (2011), por quatro agências multilaterais, a saber: $\mathrm{UNESCO}^{3}$, $\mathrm{UNICEF}^{4}$, PNUD $^{5}$ e Banco Mundial. Dessa conferência resultou a Declaração Mundial sobre Educação para Todos: satisfação das necessidades básicas de aprendizagem (1990). As NEBAS $^{6}$ são assim definidas.

Cada pessoa - criança, jovem ou adulto - deve estar em condições de aproveitar as oportunidades educativas voltadas para satisfazer suas necessidades básicas de aprendizagem. Essas necessidades compreendem tanto os instrumentos essenciais para a aprendizagem (como a leitura e a escrita, a expressão oral, o cálculo, a solução de problemas), quanto os conteúdos básicos da aprendizagem (como conhecimentos, habilidades, valores e atitudes), necessários para que os seres humanos possam sobreviver, desenvolver plenamente suas potencialidades, viver e trabalhar com dignidade, participar plenamente do desenvolvimento, melhorar a qualidade de vida, tomar decisões fundamentadas e continuar aprendendo. A amplitude das necessidades básicas de aprendizagem e a maneira de satisfazê-las variam segundo cada país e cada cultura, e, inevitavelmente, mudam com o decorrer do tempo. (ORGANIZAÇÃO DAS..., 1998, p. 3)

O Banco Mundial, em documento no qual indica as prioridades e estratégias para a educação, é mais claro ainda sobre o sentido social da educação básica, afirmando:

\begin{abstract}
A educação básica proporciona o conhecimento, as habilidades e as atitudes essenciais para funcionar de maneira efetiva na sociedade sendo, portanto, uma prioridade em todo lugar. Esses atributos incluem um nível básico de competência em áreas gerais tais como as habilidades verbais, computacionais, e a resolução de problemas. Essas competências podem ser aplicadas a uma grande variedade de empregos e permitir às pessoas adquirir habilidades e conhecimento específicos orientados para o trabalho, quando estiverem no local de trabalho. Em geral, esse nível básico inclui cerca de oito anos de escolaridade. De fato, em muitos países, o primeiro ciclo da educação secundária está sendo combinado com a educação de primeiro grau para conformar uma etapa de educação obrigatória conhecida como “educação básica”. (BM, 1995, p. 63 apud Haddad; Tommasi; Warde, 1996, p. 131).
\end{abstract}

Justificando esse sentido social atribuído à educação básica encontram-se dois argumentos: um em que se afirma ser a educação um processo que extrapola os limites da instituição escolar; outro que defende ser a educação um processo que se realiza ao longo da vida. Â educação escolar caberia, portando, garantir condições necessárias para que os indivíduos "aprendessem a aprender", estando aptos às adaptações as quais estariam sujeitos num mundo em constante mudança. Essa ideia é consubstanciada no lema amplamente difundido a partir do Relatório Educação: um tesouro a descobrir no qual quatro são os pilares da educação: aprender a conhecer, aprender a fazer, aprender a conviver e aprender a ser. (DELORS, 1996, p. 31).

Duarte (2011), em ampla análise desenvolvida sobre o lema "aprender a aprender" afirma ser este um princípio educativo nada inovador, identificando sua origem, no Brasil, 
no movimento escolanovista já no início do século XX. É necessário, assim, entender o revigoramento desse lema que adquire centralidade nas concepções pedagógicas e políticas educacionais contemporâneas no contexto de mundialização do capital em que países considerados "em desenvolvimento" ou "subdesenvolvidos" são chamados a assumir o papel que lhes cabe na divisão internacional do trabalho objetivando alavancar o processo de acumulação de capital em escala mundial. Nesse contexto é que se insere o processo de reprimarização da economia brasileira e, no seu bojo, é possível o entendimento do papel que a educação dos trabalhadores assume.

Quatro posicionamentos valorativos foram objeto de reflexão de Duarte (2011) sobre o lema "aprender a aprender" que nos ajudam a compreender o significado histórico-social dessa expressão: 1) valorização da aprendizagem que o indivíduo realiza sozinho, estando ausente outro sujeito que o ensine a aprender; 2) afirmativa de que é mais importante desenvolver um método para aprender a aprender; 3) a aprendizagem deve ser impulsionada pelos interesses e necessidades dos indivíduos; 4) a educação deve preparar o indivíduo para se adaptar a uma sociedade em constante mudança.

Esses princípios resultam em diversas decorrências para o projeto educacional em franco processo de implementação. $O$ ensino passa a ter uma conotação negativa e juntamente ocorre a desqualificação do professor, implicando num processo de desvalorização do trabalho docente e, portanto, de sua formação. A centralidade do método de aprendizagem, por sua vez, secundariza ou, levado às últimas consequências, tende a negar o próprio conhecimento científico como objeto de ensino e aprendizagem.

Articulada às duas consequências acima identificadas contidas no lema "aprender a aprender", decorre a terceira, a partir da qual, por se respeitar os interesses e necessidades dos indivíduos em processo de aprendizagem, não se pode privilegiar uma determinada concepção de mundo. A educação, assim, teria um caráter neutro e relativista. Essa posição é claramente expressa nas palavras de Piaget (apud Duarte, 2011, p. 43) para o qual:

Certamente não nos cabe prescrever à criança um ideal novo: não sabemos como será a sociedade de amanhã. Não cabe a nós inculcar na criança um ideal político, um ideal econômico, um ideal social demasiado preciso. O que devemos lhe fornecer é simplesmente um método, um instrumento psicológico fundado na reciprocidade e na cooperação.

E, por fim, os indivíduos, ao aprenderem tendo como referência o mundo em mudança, estariam preparados a conquistar seu lugar nele. Fonseca $(1998$, p. 307 apud Duarte, 2011, p. 48) nos brinda com o real significado desse princípio na citação a seguir que, apesar de longa, é necessária:

Em vez de se situarem numa perspectiva de trabalho seguro e estático, durante toda a vida, os empresários e os trabalhadores devem cada vez mais investir no desenvolvimento do seu potencial de adaptabilidade e de empregabilidade, o que é algo substancialmente diferente do que se tem praticado. O êxito do empresário e do trabalhador no século XXI terá muito que ver com a maximização das suas competências cognitivas. Cada um deles produzirá mais na razão direta de sua maior capacidade de aprender a aprender, na medida em que o que o empresário e o trabalhador conhecem e fazem hoje não é sinônimo de sucesso no futuro. [...] A capacidade de adaptação e de aprender a aprender e a reaprender, tão necessária 


\title{
Revista HIIST'TEIDBR On-line
}

para milhares de trabalhadores que terão de ser reconvertidos em vez de despedidos, a flexibilidade e modificabilidade para novos postos de trabalho vão surgir cada vez com mais veemência. Com a redução dos trabalhadores agrícolas e dos operários industriais, os postos de emprego que restam vão ser mais disputados, e tais postos de trabalho terão que ser conquistados pelos trabalhadores preparados e diferenciados em termos cognitivos.

No quadro de crise estrutural da acumulação capitalista, está em curso, como já assinalado, um processo de reprimarização da economia brasileira e de superexploração da força de trabalho. A precarização das condições do trabalho se expressa no aumento contínuo de desempregados que, segundo dados do IBGE representou, em abril de 2017, mais de 14 milhões de pessoas. Nesse contexto, a educação tem se convertido em estratégia de reprodução do capital. Como afirma Leher $(2014$, p. 6):

\begin{abstract}
Se os setores dominantes tomam de assalto a educação pública - não se limitando ao seu já amplo aparato educativo privado que alcança mais de $75 \%$ dos estudantes da educação superior - é porque, evidentemente, compreendem que imprimir a direção intelectual e moral é relevante para a reprodução do capital, especialmente na educação básica, justo onde o Estado ainda mantém grande parte das matrículas (e, evidentemente, em toda a multifacetada malha de organizações públicas e privadas de educação profissional).
\end{abstract}

Percebe-se que se trata de um Projeto Mundial para a Educação forjado internacionalmente por instituições criadas com o papel de elaborar e implementar, por meio de acordos de cooperação técnica e financeira, profundas mudanças na educação em países como o Brasil.

Segundo as especificidades de nossa formação social capitalista, as reformas democráticas nunca se efetivaram, entre elas a educacional, que seria responsável por compor os fundamentos para a constituição de um sistema nacional de educação com mínimos de homogeneidade no conjunto do país e que conferisse igualdade de oportunidades à toda população brasileira. Com o fim da ditadura, na transição para a "Nova República", houve uma reorganização do campo educacional com intensa participação dos professores proletarizados, trabalhadores da educação e entidades que congregavam pesquisadores da área, que exerceram forte pressão para que a nova Constituição Federal bem como a nova Lei de Diretrizes e Bases expressassem a construção da educação pública que forjasse de fato os fundamentos da democracia. Embora repleto de limites e dificuldades neste intento, houve conquistas importantes, como a noção ampla de educação presente na Constituição Federal (CF) de 1988, a vinculação de recursos para educação em todos os níveis do Estado, além das metas de universalização da educação e valorização do trabalho do professor. Se no campo legal houve avanços, a dificuldade para implementação dessas metas se mostrou crescente nas últimas décadas, com maior intensidade desde 2016, ano em que se iniciou a aprovação de medidas que desconfiguram os avanços essenciais da CF e da LDB (1996).

Tendo como inspiração a análise teórica de Florestan Fernandes (2006) que define que a dominação burguesa no Brasil porta a contrarrevolução sistemática, identificamos nesse bojo a formulação das atuais políticas educacionais, bem como o projeto escola sem partido, de autoria dos setores de extrema direita e que parece tecer uma complementaridade com tais políticas. Trata-se de uma estratégia de controle e direcionamento do processo formativo da massa da população ancorado numa proposta minimalista, na qual se esvazia, 
gradativamente, a escolados conhecimentos científicos e político-culturais amplos que poderiam se tornar instrumentos de crítica da ordem societária vigente. Desse modo, os três aspectos que analisaremos seriam parte de uma contrarreforma educacional em curso no país: a Base Nacional Comum Curricular; as normativas que tratam da formação de professores e o projeto escola sem partido.

\section{CONTRARREFORMA EDUCACIONAL: ASPECTOS DA POLÍTICA EDUCACIONAL CONTEMPORÂNEA}

Vivenciamos, na contemporaneidade, um processo de construção de um sentido social da educação de conformação dos sujeitos à estrutura societária vigente, o que demanda um processo de organização e gestão do processo de trabalho educativo para sua efetivação na prática pedagógica. Uma ampla contrarreforma educacional, portanto, está em curso, sua objetivação passa, necessariamente, pelos trabalhadores da educação, sobretudo os docentes que, cotidianamente, com as crianças, jovens e adultos, devem se orientar por essa proposta educativa mundializada.

Entre os diferentes aspectos que podem conformar esta contrarreforma educacional focalizaremos: 1) A construção de uma Base Nacional Comum Curricular e o esvaziamento de conteúdos da escola; correlatamente 2) As mudanças na formação de professores neste novo cenário; e, por fim, 3) A confluência desses direcionamentos da política educacional com o Projeto Escola Sem Partido.

\section{A BASE NACIONAL COMUM CURRICULAR}

A construção da Base Nacional Comum Curricular (BNCC) toma forma a partir da criação, no Brasil, do autodenominado "Movimento pela Base Nacional"7 que, segundo informações contidas no próprio site da organização é formado por

[...] um grupo não governamental de profissionais da educação que desde 2013 atua para facilitar a construção de uma Base de qualidade. O grupo promove debates, produz estudos e pesquisas com gestores, professores e alunos e investiga casos de sucesso em vários países. (MOVIMENTO PELA..., 2017).

Esse grupo é composto por mais de sessenta pessoas apoiadas por oito instituições, a saber: ABAVE (Associação Brasileira de Avaliação Educacional); CENPEC (Centro de Estudos e Pesquisas em Educação, Cultura e Educação Comunitária); CEDAC (Comunidade Educativa); CONSED (Conselho Nacional de Secretários de Educação); Fundação Lemann; Fundação Maria Cecilia Souto Vidigal; Fundação Roberto Marinho; Instituto Ayrton Senna; Instituto Inspirare; Instituto Natura; Instituto Unibanco; Todos pela Educação; UNIDIME (União Nacional dos Dirigentes Municipais de Educação).

A informação veiculada é de que a origem desse movimento se deu em 2013, contudo, não esclarece como e onde se iniciou esse processo de criação. Seria possível inferir que esse movimento teve início num Seminário Internacional realizado em New Haven, Estados Unidos, na Universidade de Yale, de 21 a 24 de abril de 2013 com o sugestivo título "Liderando Reformas Educacionais: Fortalecendo o Brasil para o Século XXI", tendo em 
vista as informações encontradas no site da Câmara dos Deputados de que uma delegação participou, em caráter de Missão Oficial ${ }^{8}$, a convite da Fundação Lemann, desse evento. No Requerimento 227/2013 CE (Câmara de Educação) consta que foram convidados os (as) Deputados(as) Alex Canziani (PTB/PR), Artur Bruno (PT/CE), Professora Dorinha Seabra Rezande (DEM/TO), Manoela D’ávila (PCdoB/RS) e Raul Henry (PMDB/PE).

Em discurso 9 proferido em Plenário, o Deputado Alex Canziani, na semana seguinte de sua participação no referido seminário afirma:

\begin{abstract}
Através desse seminário, nós pudemos acompanhar as experiências dos Estados Unidos com sua situação: o common core, cujo debate queremos trazer para o Brasil. Trata-se do currículo único para a educação brasileira. O que nós vemos hoje no Brasil? Cada Município, cada Estado tem o seu currículo, e, muitas vezes, sem ter claro aquilo que as crianças devem aprender a cada ano de ensino. A ideia é que nós possamos, através dos secretários estaduais de educação, através dos secretários municipais, do próprio MEC, fazer uma discussão sobre currículo. (BRASIL, 2013, grifo nosso).
\end{abstract}

Enseja-se, portanto, a definição de um documento de política curricular que seja parâmetro a ser seguido por todas as unidades escolares públicas e privadas em todo território nacional. Isso porque, no conjunto do trabalho pedagógico, ganha relevância a definição das finalidades formativas a serem perseguidas e os conteúdos por meio dos quais se atingiria tais objetivos. A BNCC, portanto, em conjunto com o Sistema Nacional de Avaliação da Educação Básica (SAEB) por meio de seus mecanismos de aferição dos resultados do processo educativo, são instrumentos estratégicos no processo de implementação do Projeto de Educação em curso no Brasil. Em outras palavras, criam-se os mecanismos de gestão da educação nacional com vistas a dar direção ao desenvolvimento do trabalho pedagógico levado a cabo pelos trabalhadores da educação, sobretudo pelos docentes.

Como afirmado no site da Fundação Lemann "Com a Base Nacional Comum Curricular, as expectativas de aprendizado e critérios de qualidade ganham transparência e podem ser aplicadas e cobradas com maior eficiência"10.

Dentre vários aspectos que poderiam ser mencionados, tanto do processo de elaboração da BNCC quanto de seu conteúdo, destacam-se dois que nos ajudam a elucidar e articular o sentido atribuído à educação brasileira no contexto de reprimarização da economia e mudanças decorrentes do mundo do trabalho: o processo antidemocrático de sua elaboração e o realce atribuído ao direito à aprendizagem.

Para a elaboração do documento preliminar da BNCC foi instituída uma comissão por meio da Portaria MEC 592 de 17 de junho de 2015, definindo 116 especialistas que comporiam esse grupo responsável tanto pela elaboração do documento preliminar quanto de relatórios resultantes da discussão pública deste documento. Com a indicação de participação de membros de todas as unidades, coube ao CONSED e à UNIDIME a tarefa de atribuir aos membros desta comissão as responsabilidades referentes à gestão do processo elaboração do documento por áreas de conhecimento e seus respectivos componentes curriculares. 
Pouco mais de três meses após emissão da referida Portaria o documento preliminar da BNCC foi apresentado publicamente em um Seminário realizado em 24 e 25 de setembro em Belo Horizonte na Universidade Federal de Minas Gerais. Nesta ocasião, o Sr. Ítalo Dutra, então na condição de Diretor de Currículo da Secretaria de Educação Básica do MEC anunciou que, por meio do PAR (Plano de Ações Articuladas), o MEC recebeu mais de três mil documentos curriculares elaborados pelos Estados e Municípios. Contudo, esses documentos oriundos de experiências diversas de construção e implementação de propostas curriculares não são referenciados em nenhuma das três versões da BNCC, nem é possível localizar estudos desenvolvidos desses documentos. Pergunta-se, então, quais as bases empíricas nas quais a BNCC se fundamentou? Essas bases não são explicitadas em nenhuma das versões da BNCC, o que coloca em questão se foram levadas em consideração as experiências históricas desenvolvidas pelos trabalhadores da educação.

Um outro aspecto a ser considerado refere-se à redução, a nosso ver, do conceito de educação tal qual expresso na Constituição Federal (CF) de 1988 em seu artigo 205:

\begin{abstract}
A Educação, direito de todos e dever do Estado e da família, será promovida e incentivada com a colaboração da sociedade, visando ao pleno desenvolvimento da pessoa, seu preparo para o exercício da cidadania e sua qualificação para o trabalho. (BRASIL, 1988).
\end{abstract}

A Educação inscrita na CF é entendida como um direito social dentre outros como saúde, moradia. A garantia de direitos sociais é necessária em formações sociais marcadas por altos índices de desigualdades que impedem o pleno desenvolvimento de todos os seres humanos, indiscriminadamente. Esse sentido atribuído à educação foi forjado na luta pela redemocratização do país em que diferentes setores sociais, por meio da organização de movimentos sociais populares, buscaram influir nas políticas públicas, de modo geral, e, especificamente, na educação.

Contrariamente a esse sentido social deformação humana, a BNCC traz um outro entendimento desse conceito restringindo-o ao direito à aprendizagem em que a responsabilidade do processo de desenvolvimento é individualizada passando a ser parametrizada, numa ponta do processo, pelos objetivos de aprendizagem por meio da BNCC e, na outra, pela avaliação dos resultados por meio de testes estandardizados em que o dado prioritário é o desempenho de cada aluno, num claro processo, iniciado na década de 1990, de privatização do processo educativo tendo como referência a lógica empresarial. Como bem esclarece Sanfelice (2000, p. 155):

Sempre de acordo com a concepção individualista e a lógica do mercado, é preciso que se diga ainda que o neoliberalismo privatiza tudo, inclusive o êxito e o fracasso social do indivíduo. Não é diferente no que diz respeito ao sucesso e ao fracasso escolar.

\title{
MUDANÇAS NA FORMAÇÃO DE PROFESSORES
}

Para que haja efetivação dessa mudança de sentido da educação que está na base da política educacional na conjuntura atual faz-se necessário que as (os) trabalhadoras (es) da educação sejam impelidas a atuar com base e em prol desse projeto. Para isso, dois são os 


\title{
Revista HIISTEIDBR On-line
}

focos de ação levados a cabo de forma articulada: criação e implementação de mecanismos de gestão do processo de trabalho pedagógico por meio dos quais se estabelece os limites institucionais no qual os sujeitos atuam e os processos sistematizados de formação profissional desses sujeitos, intencionando conformá-los à proposta em curso. Podemos considerar que a BNCC, articulada ao SAEB, são partes constitutivas do processo de regulação e controle do processo de trabalho e as formações iniciais e continuadas se constituem como elementos do segundo foco de ações.

Historicamente, as mudanças nos processos de formação de professores têm ocorrido de forma articulada às reformas educacionais em curso. Podemos citar, a título de exemplo, a reforma educacional paulista da década de 1890 que iniciou com propostas de reformulação das Escolas Normais, então lócus de formação docente. Processo semelhante ocorreu na década de 1930 com a transformação, no bojo do movimento da escola nova, das Escolas Normais paulista e carioca em Institutos de Educação sendo, posteriormente, incluídas na estrutura das primeiras universidades brasileiras. E assim sucessivamente. Diante dessa constatação, as políticas e processos de formação docente só podem ser entendidas no contexto da política educacional nacional e esta como parte constitutiva do conjunto das mudanças sociais em curso. Assim, é possível afirmar que

\begin{abstract}
Com a organização de escolas surge a necessidade de se pensar nos profissionais que nela deveriam atuar a fim de organizar e direcionar o processo educativo do "novo" homem. A educação escolar, assim, se constitui no campo de atuação profissional dos educadores. O processo educativo passa a ser regulado por dois mecanismos: a organização intencional e sistemática tanto administrativa quanto pedagógica das escolas e, também, pela regulação intencional e sistemática do processo de formação dos professores por meio da criação de cursos específicos. Conforme a instituição escolar vai se ampliando e se modificando em função das mudanças que vão ocorrendo na sociedade, amplia-se e se modifica, também, os processos de formação dos profissionais da educação. (COUTINHO; SACCOMANI, 2015, p. 234).
\end{abstract}

Defende-se, aqui, a tese de que a formação docente ocupa lugar estratégico no processo de implementação do projeto educacional atual. Isso porque, sem sujeitos que a assumam na sua prática social, não há efetivação de nenhuma proposta.

Shiroma e Evangelista (2007), em artigo tendo como fontes os documentos oficiais de projetos educacionais destinados à América Latina e Caribe, desenvolvidos por organismos internacionais, buscam analisar "[...] o modo pelo qual essas organizações procuram construir o professor como protagonista e, ao mesmo tempo, como obstáculo à reforma educacional, desqualificando-o teórica e politicamente". (p. 531). Segundo as mesmas autoras, as diretrizes emanadas desses projetos internacionais encontram expressão na formação de professores com a Resolução número CNE 1/2006 que define as Diretrizes Curriculares Nacionais para o Curso de Pedagogia. Nesta

[...] explicitam, simultaneamente, uma restrição nos conteúdos da formação docente, centrados numa perspectiva de saber instrumental, e um alargamento das funções docentes incorporando, por exemplo, tarefas de gestão e outras não diretamente ligadas ao ensino (Evangelista, 2006). Manifesta-se, aqui, a preocupação com a eficiência e a eficácia do trabalho docente, inseridas numa lógica racionalizadora, técnica, pragmática, que encontra na defesa abstrata do uso 


\section{Revista HIIST'TEIDBR On-line}

das tecnologias da informação e comunicação sua expressão mais acabada. (EVANGELISTA; SHIROMA, 2007, p. 536).

Freitas (2007) traz à reflexão a questão da ampliação, diversificação e flexibilização de cursos de formação de professores no bojo desse projeto educacional neoliberal, em contraposição à proposta dos educadores organizados em entidades próprias, como a ANFOPE (Associação Nacional pela Formação dos Profissionais da Educação), que defende que a formação docente ocorra no âmbito das Universidades Públicas, como lócus privilegiado em que se possibilitaria a articulação de uma sólida formação teórico-científica com os fundamentos práticos da educação.

Alarmantes são os dados ${ }^{11}$ coletados junto ao MEC referentes aos cursos de Pedagogia demonstrando que desde a origem deste em 1939 até 2006 foram criados 1816 cursos no Brasil. De1998 a 2006 instituíram-se 1.312 cursos de Pedagogia, representando 72,25\% deste total, contrapondo-se aos 504 cursos abertos de 1939 a 1997. Em 9 anos foram abertos $160 \%$ mais cursos do que em 58 anos. Cruzando os dados (ano de criação, esfera administrativa e Região do Brasil), observou-se que, dos 504 cursos criados em instituições públicas, 395 foram nas Regiões Norte e Nordeste sendo a participação da iniciativa privada reduzida a valores próximos a $35 \%$. O contraste pode ser percebido ao se comparar os dados dessas regiões com os da Região Sudeste, onde, no mesmo período, foram criados 409 cursos em instituições privadas de ensino contra somente 37 em instituições públicas. Temos um crescimento vertiginoso, sobretudo em instituições de ensino superior privadas, acrescentando-se a isso a retomada de cursos em nível médio para formação de professores de educação infantil e ensino fundamental, além da possibilidade de outros lócus de formação docente como os Institutos Superiores de Educação. (FREITAS, 2007).

É por estas vias que vão se produzindo e reproduzindo as desigualdades na formação de professores, que persistem em nosso país há muitas décadas. A necessidade de expansão da escolarização, o reduzido investimento público na educação e a impossibilidade do Estado - mínimo - prover os recursos necessários que garantam a expansão massiva da educação superior pública - universitária, presencial - e a formação de qualidade elevada para todos os professores alteram significativamente o caráter da formação em nosso país. As iniciativas atuais de massificação, por intermédio da UAB, cumprem as metas estatísticas e conformam os professores a uma concepção de caráter subordinado, meramente instrumental, em contraposição à concepção de educador de caráter sócio-histórico, dos professores como profissionais da educação, intelectuais essenciais para a construção de um projeto social emancipador que ofereça novas possibilidades à educação da infância e da juventude. (p. 1214)

Essa tendência apontada por Freitas (2007) pode ser percebida, ainda que menos acentuadamente, na Resolução CNE 2 de 2015 que traz uma diminuição da carga horária para 2.200 horas destinadas aos conhecimento científico-conceituais das chamadas Ciências da Educação a serem subdivididas em três núcleos, as saber:

I - núcleo de estudos de formação geral, das áreas específicas e interdisciplinares, e do campo educacional, seus fundamentos e metodologias, e das diversas realidades educacionais 


\section{Revista HIISTEIDBR On-line}

II - núcleo de aprofundamento e diversificação de estudos das áreas de atuação profissional, incluindo os conteúdos específicos e pedagógicos, priorizadas pelo projeto pedagógico das instituições, em sintonia com os sistemas de ensino

III - núcleo de estudos integradores para enriquecimento curricular. (BRASIL, $2015)^{12}$.

Coroando essa tendência com caráter fragmentador e esvaziador de conteúdo teóricocientífico do processo de formação docente encontra-se a Deliberação 154 do Conselho Estadual de Educação do Estado de São Paulo publicada no Diário Oficial do Estado em 01 de junho de 2017, tendo sido relatoras as Conselheiras Guiomar Nano de Mello e Rose Neubauer, por meio da qual são estabelecidas diretrizes complementares para formação docente, dando nova redação à Deliberação CEE 111/2012.

O conceito central dessa deliberação é o de PCC (Prática como Componente Curricular), esclarecendo-se que este deverá tomar como referência a BNCC.

O conceito da PCC implica numa mudança na própria cultura pedagógica do ensino superior de formação de professores, no sentido de aproximá-la do tipo de formação que se ministrava nos antigos cursos normais, nos quais os estudantes cursavam as disciplinas do ensino médio e ao mesmo tempo se preparavam para ser docentes. Aprender os objetos de conhecimento e aprender a ensiná-los eram processos formativos que aconteciam sob um único e mesmo escopo ou projeto pedagógico, às vezes sob a docência do mesmo professor. (SÃO PAULO, 2017, p. 4) ${ }^{13}$.

[...] a referência será o que vai prescrever a Base Nacional Comum Curricular da Educação Básica (BNCC). (SÃO PAULO, 2017, p. 5) $)^{14}$.

Entende-se, a partir daí, o lugar e o papel atribuído à formação de professores na política educacional vigente e o prenúncio feito por Freitas (2007) ao analisar a tendência inscrita nas Diretrizes Curriculares Nacionais para o Curso de Pedagogia de 2006. A deliberação do CEE, no artigo $4^{\circ}$ define a distribuição que deve ter as 3.200 horas do curso:

I - 600 (seiscentas) horas dedicadas à revisão e enriquecimento dos conteúdos curriculares do ensino fundamental e médio;

II - 1.400 (hum mil e quatrocentas) horas dedicadas ao estudo dos conteúdos específicos e dos conhecimentos pedagógicos que garantam a transposição didática ou outras mediações didáticas e a apropriação crítica desses conteúdos pelos alunos;

III - 400 (quatrocentas) horas de prática como componente curricular - PCC adicionadas às 1.400 horas do item anterior e distribuídas ao longo do percurso formativo do futuro professor, em conformidade com o item 2 da Indicação CEE $n^{\circ} 160 / 2017$, referente a esta Deliberação;

IV - 400 (quatrocentas) horas para estágio supervisionado; V - 400 (quatrocentas) horas para formação nas demais funções previstas na Resolução $\mathrm{CNE} / \mathrm{CP} \mathrm{n}^{\circ}$ 01/2006. (SÃO PAULO, 2017, p. 4) ${ }^{15}$.

E a deliberação prossegue com um grau de detalhamento, diferentemente das normas nacionais vigentes, em que se define os componentes curriculares a serem objeto de ensino e aprendizagem em cada um dos blocos em que foram subdivididas as 3.200 horas para integralização do curso de Pedagogia indicando, explicitamente, que estes devem se ater aos conhecimentos a serem objeto de ensino e aprendizagem da educação básica em consonância 
com a BNCC. Nesta deliberação a tendência anunciada já nas Diretrizes Curriculares Nacionais para o Curso de Pedagogia em 2006 se apresenta da forma mais acabada e objetiva excluindo, por determinação legal, toda a tradição teórico-conceitual ${ }^{16}$ produzida na Pedagogia, entendida como Ciência da Educação que, no Brasil, encontra espaço acadêmico para desenvolvimento no bojo do projeto renovador na década de 1930 por meio da incorporação dos Institutos de Educação de São Paulo e do Rio de Janeiro às duas primeiras universidades brasileiras, a Universidade de São Paulo (USP) e a Universidade do Distrito Federal, atual Universidade Federal do Rio de Janeiro (UFRJ).

Assim, intensificam-se os mecanismos de controle e regulação do processo educativo da população brasileira. Em que professores são formados cada vez mais dentro de uma perspectiva minimalista. Neste contexto, se agrega o projeto escola sem partido, que vem trazer temor e censura para as discussões realizadas nas salas de aula.

\section{PROJETO ESCOLA SEM PARTIDO}

O Projeto Escola Sem Partido surgiu em 2004, por autoria do advogado Miguel Nagib e apoiado por dois deputados de direita, Flávio e Carlos Bolsonaro. Diante da intensificação da crise econômica e da crescente instabilidade política o projeto ganhou repercussão, passando a influenciar projetos de lei em âmbito municipal, estadual e federal. A premissa de que parte o projeto anuncia um falseamento da realidade escolar brasileira, uma vez, que sabidamente estamos diante de precárias condições escolares, em que vigora a falta de recursos, ausentam-se boas condições de trabalho para os professores, com fortes valores conservadores, com uma laicidade que nunca se concretizou. Afirmar que professores são "doutrinadores" e que estaria entre os principais problemas educacionais consiste em desviar-se dos problemas fundamentais em prol de uma desqualificação e esvaziamento do sentido da escola:

\footnotetext{
Esse falseamento da realidade da escola, porém, é um ponto de partida estratégico para difundir os propósitos reacionários do ESP. Não expressa sua ignorância, embora eles, de fato, o sejam em relação a problemas educacionais. Por meio desse falseamento, os PLs 7180/2014 e 867/2015 vão ao encontro de outras tendências da política educacional brasileira dos últimos anos, em que pesem as propostas de esvaziamento do ensino e de seus conteúdos (por proibir o que é "político" ou por indicar que "não há verdade"), a tendência de intensificação dos instrumentos de controle sobre o trabalho docente (por exigência de "produtividade"), as noções superficiais que desistoricizam o sujeito-educando (por valorizar sua individualidade "moral" ou por conceber uma aprendizagem como produto natural e direto de sua condição vital). Trata-se, assim, de um projeto deliberadamente construído na base da desqualificação sistemática da escola e dos seus profissionais. (MINTO, RODRIGUES, GONZALEZ, 2016, p. 2).
}

O Projeto Escola Sem Partido apresenta estreita consonância com os objetivos da política educacional que se vinculam ao estreitamento do currículo expresso na Base Nacional Comum Curricular, bem como dos fundamentos que a justificam, transformando o direito à educação em direito à aprendizagem. Esta mudança configura a redução de sentido na formação humana, a educação enquanto sentido amplo, voltada para preparar para vida em uma democracia, se reduz à acesso a conhecimentos mínimos, aferidos por ampla 
testagem atrelada à busca pela garantia de que os objetivos de aprendizagem foram alcançados.

No Projeto, entende-se que o professor deve se restringir a transmitir certos conteúdos aos estudantes. Não haveria identificação entre "liberdade de ensinar" e "liberdade de expressão", nesse sentido o trabalho do professor transforma-se em algo mecânico, em que o conhecimento não encontra espaço para uma construção conjunta a partir da liberdade de ideias, de confronto de posições. A relação do estudante com o conhecimento converte-se em uma relação puramente de consumo de alguns conhecimentos o que se coaduna muito bem com a conversão do direito à educação em direito à aprendizagem:

[...] argumentos como o da oposição entre liberdade de ensino e liberdade de expressão tentam confundir os posicionamentos que os proponentes do "Programa Escola sem Partido" desejam ocultar. Liberdade de expressão não é restrita a nenhum espaço e deve, portanto, ser lida em conjunto com a liberdade de ensinar. Ensinar nunca é um ato do qual se dissociam os posicionamentos pessoais e socialmente construídos dos sujeitos envolvidos, razão pela qual, não consideramos que o professor só ensina e o estudante só aprende: ambos mantêm relações recíprocas, de trocas enriquecedoras, mutuamente determinadas por suas vivências, experiências e, evidentemente, posicionamentos assumidos perante a vida, a sociedade, o mundo, o trabalho. Há que se destacar ainda que é a liberdade de pensamento e as diferenças entre posições de diferentes sujeitos que permitem que ao longo de sua trajetória escolar, cada estudante possa interagir com um conjunto heterogêneo de outros estudantes e de docentes, cada qual com suas posições e perspectivas, tornando o processo educativo ainda mais rico e democrático. Sem essa troca, qualquer atividade pedagógica se inviabiliza, pois seria necessário supôla sem elementos a serem trocados. Sequer o conhecimento é possível se não se pressupõe sujeitos em situação social de intercâmbio, vinculados a contextos reais e também a interesses concretos e distintos. Quando se assume que tudo o que o professor diz em sala de aula é, mecânica e automaticamente, internalizado pelo estudante, incorre-se em profundo equívoco, sem qualquer fundamento científico. (UNIVERSIDADE ESTADUAL DE CAMPINAS, 2017).

Assim como não há fundamento científico que embase tal apreensão da relação entre professor e estudante, é preciso considerar também que a ciência é construída justamente pelo confronto de ideias, experiências, teses. Censurar o debate de ideias no interior das escolas consiste em atacar a possibilidade de que o conjunto dos estudantes acessem os debates mais avançados nas diferentes temáticas. O caso das discussões de gênero é emblemática neste sentido. Um dos argumentos favoráveis ao projeto escola sem partido vincula-se à interdição de temas como sexualidade, violência contra mulheres, lésbicas, gays, bissexuais, impedindo-se que sejam tratados com o devido rigor no local apropriado para conteúdos provenientes da produção científica segundo pesquisas realizadas em diferentes países.

\section{CONSIDERAÇÕES FINAIS}

Procurou-se relacionar as mudanças do âmbito econômico por que tem passado o país, expressa na regressão de sua estrutura econômica, desde os anos de 1990 e intensificada na última década, com o que aqui denominamos de "contrarreforma educacional". Então, 
desenvolvemos as perguntas: Qual educação o trabalhador necessita em um país que reitera sua condição dependente e subdesenvolvida? A regressão na estrutura produtiva seria um dos fundamentos explicativos de uma educação esvaziada de conteúdos e sentidos? Estudos recentemente publicados como o de Sampaio Junior (2017) e o de Braga (2017) mostraram a forte tendência à reprimarização da economia, ao fortalecimento do eixo da economia intensiva em recursos naturais e à concentração das oportunidades de trabalho no setor de serviços, engrossando as fileiras dos trabalhadores superexplorados denominados de "precariato". Estas são atividades econômicas que exigem trabalhadores com formação minimalista, ao mesmo tempo em que a regressão econômica provoca mais desemprego e insatisfação com o sistema social.

Neste cenário, as parcas conquistas do campo legal presentes na Constituição Federal de 1988 e na Lei de Diretrizes e Bases de 1996 parecem se esvair. Trata-se de desconstruir uma visão ampla de educação, que articulava formação para o trabalho e para a cidadania, tendo como foco o pleno desenvolvimento da pessoa. Percebemos como retrocessos as políticas educacionais que vêm sendo implementadas num movimento de contrarreforma educacional, já que contraria os anseios que ligavam a educação à democracia.

A Base Nacional Comum Curricular traz um entendimento de educação restrito ao direito à aprendizagem, em que o processo de desenvolvimento é individualizado passando a ser parametrizado, avaliado em testes estandartizados. Trata-se de reduzir ao máximo os conteúdos trabalhados nas escolas o que se coaduna muito bem com o caráter fragmentador e esvaziador do conteúdo teórico-científico no processo de formação docente presente nas novas normativas. Assim, percebemos que a formação de professores está imbricada nas determinações recíprocas entre educação e trabalho, num momento em que o Brasil se insere de maneira ainda mais subalterna na divisão internacional do trabalho.

Intensificam-se os mecanismos de controle e regulação do processo educativo da população brasileira, ao mesmo tempo em que adquire influência nesses espaços o projeto escola sem partido, proposta formulada dentro do espectro político da extrema direita, que pretende cercear as discussões no interior da escola, com a escusa de que deve haver neutralidade e ausência de partido, falseando a realidade escolar, num projeto deliberado de desqualificação sistemática da escola e dos seus profissionais.

\section{REFERÊNCIAS}

ALTMANN, H. Influências do Banco Mundial no projeto educacional brasileiro. Educação e Pesquisa, São Paulo, v. 28, n. 1, p. 77-89, jan./jun. 2002.

BRAGA, R. A rebeldia do precariado. Trabalho e neoliberalismo no Sul global. São Paulo: Boitempo, 2017.

BRASIL. CNE. Resolução n. 2/2015. Define as Diretrizes Curriculares Nacionais para a formação inicial em nível superior (cursos de licenciatura, cursos de formação pedagógica para graduados e cursos de segunda licenciatura) e para a formação continuada. 
BRASIL. Congresso Nacional. Câmara dos Deputados. Alex Canziani, discurso proferido em Plenária em 30/04/2017. Disponível em: <http://www.camara.leg.br/ internet/sitaqweb/TextoHTML.asp?etapa $=3 \&$ nuSessao $=093.3 .54 .0 \&$ nuQuarto $=80 \&$ nuOra dor $=2 \&$ nuInsercao $=0 \&$ dtHorarioQuarto $=11: 38 \& s g F a s e S e s s a o=B C \% 20 \% 20 \% 20 \% 20 \% 20$ $\% 20 \% 20 \% 20 \&$ Data $=30 / 04 / 2013 \&$ txApelido $=$ ALEX $\% 20$ CANZIANI\&txEtapa $=$ Com $\% 20 \mathrm{r}$ eda\%C3\%A7\%C3\%A3o\%20final>. Acesso em: 01 nov. 2017.

BRASIL. Conselho Nacional de Educação. Resolução n. 1 de 2006. Estabelece as Diretrizes Curriculares Nacionais para o Curso de Pedagogia.

BRASIL. Constituição (1988). Constituição da República Federativa do Brasil. Brasília, DF: Senado Federal, 1988.

BRASIL. Ministério da Educação. Portaria 592 de 17 de junho de 2015. Diário Oficial a União, n. 114, seção 1, 2015. Disponível em:

<http://portal.mec.gov.br/index.php?option=com_docman\&view=download\&alias=21361port-592-bnc-21-set-2015-pdf\&Itemid=30192>. Acesso em: 01 nov. 2017

CANO, W. A desindustrialização no Brasil. Texto para discussão. Campinas, SP: IE/UNICAMP. n. 200, jan. 2012.

CARNEIRO, R. de M. Impasses do desenvolvimento brasileiro: a questão produtiva. Textos para discussão n. 153 IE/Unicamp, 2008.

DELORS, J. Relatório Educação: um tesouro a descobrir, 1996.

DUARTE, N. Vigotski e o "aprender a aprender": crítica às apropriações neoliberais e pós-modernas da teoria vigotskiana. 5. ed. rev. Campinas, SP: Autores Associados, 2011.

ESPÓSITO, M. A importância do capital internacional nas transformações na estrutura produtiva brasileira. 2016. 192 f. Dissertação (Mestrado em Ciências Econômicas) - Universidade Estadual de Campinas, Campinas, 2016.

EVANGELISTA, O.; SHIROMA, E. O. Professor: protagonista e obstáculo da reforma. Educação e Pesquisa, São Paulo, v. 33, n. 3, p. 531-541, set./dez. 2007.

FERNANDES, F. A revolução burguesa no Brasil. São Paulo: Globo, 2006.

FREITAS, H. C. L. de. A (nova) política de formação de professores: a prioridade postergada. Educ. Soc., Campinas, v. 28, n. 100 -Especial, p. 1203-1230, out. 2007.

FUNDAÇÃO LEMANN. Centro Lemann para o empreendedorismo e inovação na educação brasileira. Disponível em: <http://www.fundacaolemann.org.br/centro-lemann em-stanford/>. Acesso em: 01 nov. 2017.

LEHER, R. Organização, Estratégia Política e o Plano Nacional de Educação. Marxismo 21, 2014. Disponível em: <http://marxismo21.org/wp-content/uploads/2014/08/R-Leher- 
Estrat\%C3\%A9gia-Pol\%C3\%ADtica-e-Plano-Nacionaleduca\% C3\% A7\%C3\%A3o.pd f>. Acesso em: 22 set. 2017.

MINTO, L. W.; RODRIGUES, F. C.; GONZALEZ, J. A. Notas sobre "Escola sem Partido". Marxismo 21, 2016. Disponível em: <https://marxismo21.org/wp-content/ uploads/2016/10/Notas-sobre-Escola-Sem-Partido.pdf>. Acesso em: 31 out. 2017.

MOVIMENTO PELA BASE NACIONAL COMUM. Quem somos. Disponível em: <http://movimentopelabase.org.br/>. Acesso em: 01 nov. 2017.

NASSIF, A. Há evidências de desindustrialização no Brasil? Texto para discussão, n. 108, Rio de Janeiro: Ed. da BNDES, jul. 2006.

ORGANIZAÇÃO DAS NAÇÕES UNIDAS PARA A EDUCAÇÃO, A CIÊNCIA E A CULTURA. UNESCO. Declaração Mundial sobre Educação para Todos: satisfação das necessidades básicas de aprendizagem. 1998.

PRADO JUNIOR, C. Formação do Brasil Contemporâneo. São Paulo: Publifolha, 2000.

PROGRAMA DAS NAÇÕES UNIDAS PARA O DESENVOLVIMENTO. ONU. 2017. Disponível em: <http://www.br.undp.org/content/brazil/pt/home/idh0.html>. Acesso em: 01 nov. 2017.

RODRIGUES, F. de C. MST: formação política e reforma agrária nos anos de 1980. 2013. 187 f. Tese (Doutorado em Educação) - Universidade Estadual de Campinas, Campinas, 2013.

SACCOMANI, M. C. da. S.; COUTINHO, L. C. Da formação inicial de professores à formação continuada: contribuições da pedagogia historico-crítica: na busca de uma formação emancipadora. Germinal: Marxismo e Educação em Debate, Salvador, v. 7, n. 1, p. 233-242, jun. 2015.

SAMPAIO JUNIOR, P. de A. Crônica de uma morte anunciada. Crítica à economia política de Lula e Dilma. São Paulo: Amarante, 2017.

SANFELICE, J. L. O modelo econômico, educação, trabalho e deficiência. In LOMBARDI, J. C. (Org.). Pesquisa em Educação: História, Filosofia e Temas Transversais. 2. ed. Campinas, SP: Autores Associados, HISTEDBR; Caçador, SC: Ed, da UnC, 2000.

SÃO PAULO (Estado). Conselho Estadual de Educação, São Paulo. Deliberação n. 154 de 2017. Dispõe sobre a alteração da Deliberação CEE 111/2012. Diário Oficial Poder

Executivo, São Paulo, seção 1, 2017. Disponível em: <https://desaocarlos.educa cao.sp.gov.br/doe-07062017/>. Acesso em: 01 nov. 2017.

SÃO PAULO (Estado). Deliberação CEE 154, 2017. Dispõe sobre alteração da Deliberação CEE nº 111/2012. 
SHIROMA, E. O.; MORAES, M. C. M. de.; EVANGELISTA, O. Política Educacional. 4. ed. Rio de Janeiro: Lamparina, 2011.

\section{TOMMASI, L. de; WARDE, M. J.; HADDAD, S. (Org.). O Banco Mundial e as \\ Políticas Educacionais. 2. ed. São Paulo: Cortez, 1996.}

UNIVERSIDADE ESTADUAL DE CAMPINAS. Faculdade de Educação. Parecer técnico sobre Projeto de Lei ordinária n. 213/2017. 2017. Disponível em: <https://www. fe.unicamp.br/pf-fe/noticia/3345/parecer_escola_sem_partido.pdf $>$. Acesso em: 31 out. 2017.

\section{Notas}

\footnotetext{
${ }^{1}$ Doutora em Educação pela Faculdade de Educação - Unicamp. Grupo de Pesquisa Histedbr. Professora do Departamento de Filosofia e História da Educação - DEFHE - da Faculdade de Educação da Unicamp.fabicassia@yahoo.com.br.

${ }^{2}$ Doutora em Educação pela Faculdade de Educação - Unicamp. Professora da Universidade Federal de São Carlos - UFSCar, campus Sorocaba, Departamento de Ciências Humanas e Educação do Centro de Ciências Humanas e Biológicas. lucscoutinho@gmail.com.

${ }^{3}$ Organização das Nações Unidas para a Educação, a Ciência e a Cultura.

${ }^{4}$ Fundo das Nações Unidas para o Desenvolvimento.

${ }^{5}$ Programa das Nações Unidas para o Desenvolvimento.

${ }^{6}$ NEBAS: necessidades básicas de aprendizagem.

${ }^{7}$ http://movimentopelabase.org.br/

${ }^{8} \mathrm{http}: / /$ www.camara.gov.br/proposicoesWeb/fichadetramitacao?idProposicao=567041. Acesso em: 01 nov. 2017.

${ }^{9}$ http://www.camara.leg.br/internet/sitaqweb/TextoHTML.asp?etapa=3\&nuSessao=093.3.54.O\&nuQuart $\mathrm{o}=80 \&$ nuOrador $=2 \&$ nuInsercao $=0 \&$ dtHorarioQuarto $=11: 38 \& \operatorname{sgFaseSessao}=\mathrm{BC} \% 20 \% 20 \% 20 \% 20 \% 20 \% 20$ $\% 20 \% 20 \& D a t a=30 / 04 / 2013 \&$ txApelido=ALEX\%20CANZIANI\&txEtapa=Com\%20reda\%C3\%A7\%C3\%A 3o\%20final. Acesso em: 01 nov. 2017.

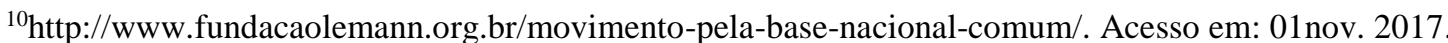

${ }^{11}$ Dados coletados pelas autoras.

${ }^{12}$ CNE, Resolução n. 2/2015, Artigo 12

${ }^{13}$ SÃO PAULO. Deliberação CEE 154, 2017, p. 4

${ }^{14}$ SÃO PAULO. Deliberação CEE 154, 2017, p. 5

${ }^{15}$ SÃO PAULO. Deliberação CEE 154, 2017, p. 4

${ }^{16}$ Para aprofundamento dos estudos da tradição teórica da Pedagogia sugere-se a leitura de: SAVIANI,

Dermeval. A Pedagogia no Brasil: história e teoria. Campinas, SP: Autores Associados, 2008.
}

Submetido em: 11/08/2017

Aprovado em: 11/09/2017 